\section{P2-473 PRESENT TREND OF CERVICAL CANCER SCREENING IN BHARATPUR, NEPAL}

doi:10.1136/jech.2011.142976m.1

${ }^{1} \mathrm{~A}$ T Sherpa (Lama), ${ }^{*} \mathrm{~J}_{\mathrm{J}}$ Sundby, ${ }^{3} \mathrm{M}$ Nygard, ${ }^{4} \mathrm{~S}$ Franceschi, ${ }^{4} \mathrm{G}$ Clifford. ${ }^{1}$ Kist Medical College, Lalitpur, Nepal; ${ }^{2}$ University of Oslo, Oslo, Norway; ${ }^{3}$ Cancer Registry, Oslo, Norway; ${ }^{4}$ International Agency for Research on Cancer, Lyon, France, French Southern Territories

Introduction According to Alliance for Cervical Cancer Prevention (ACCP) 2004, cervical cancer is the most common form of cancer among women in developing countries. According to hospital based data, in Nepalese women it is the most common cancer. Pap smear is the very significant screening test for reduction of incidence and mortality from cervical cancer. WHO recommends high coverage $(80 \%)$ and screening of the population at risk is utmost importance but many developing countries have failed to accomplish this.

Objective To evaluate cervical cancer screening coverage of women in Bharatpur.

Methods Population based cross sectional study was done from October 2006 to March 2007. 1547 ever married women aged 15-59 were selected with cluster randomisation procedure from Bharatpur municipalities. Cervical cancer screening was conducted in collaboration with IARC, France and cancer hospital in Bharatpur. Ethical clearance was sought from Nepal Health Research council. Face to face interviews were performed using a standard questionnaire to elicit information about number of Pap test in the past that they had.

Results Our study result for women who had Pap smear taken at least once in their lifetime showed $29 \%$ for 405 women who are age group $16-29$ and $46.6 \%$ for 446 women with age group 30-44.

Conclusion Present opportunistic cervical cancer screening in Bharatpur is directed towards screening significant proportion of women with less risk. This should be discouraged and focus on risk group of women with $35-45$ years of age.

\section{P2-474 FAMILIAL PREDICTORS OF VARIABILITY IN PRE-SCHOOL CHILDREN'S HEALTH: THE LIFEWAYS CROSS GENERATION COHORT STUDY}

doi:10.1136/jech.2011.142976m.2

A Shrivastava, ${ }^{*}$ C Murrin, C Kelleher, for the Lifeways Cross Generation Cohort Study Steering Group. Health Research Board Centre for Diet and Health Research, School of Public Health, Physiotherapy and Population Science, University College Dublin, Dublin 4, Ireland

Introduction The child's health in first 5 years of growth has critical adult and intergenerational consequences. Material, psycho-social and lifestyle factors are principal pathways determining health inequalities in children, and families constitute significant contributory micro-ecosystems. We examined the relationship of familial demographic, social and behavioural predictors with self-reported health (SRH) by mothers of their children, followed prospectively from ante-natal recruitment. SRH has been established as a valid measure of morbidity.

Methods Of 1082 original birth families, 547 mothers responded, when children averaged age 5 , at school entry point. Univariate associations were first analysed between SRH of children and 4 groups of characteristics (family-related, child-related, mother-related and father-related). A multivariable logistic regression analysis then re-examined the statistically qualifying predictors.

Results In univariate analysis, the following were associated with rating of child's SRH as excellent or very good: families where father participated also in the study [OR $(95 \% \mathrm{CI})=2.1$ (1.0 to 4.3$)$ ], families not entitled to means-tested healthcare [OR $(95 \% \mathrm{CI})=2.1$ (1.0 to 4.3)], families with high weekly household income [OR $(95 \%$ $\mathrm{CI})=3.0$ (1.6 to 5.9)], mothers' own SRH positive $[\mathrm{OR}(95 \% \mathrm{CI})=5.1$
(2.6 to 9.9)], mothers consuming lower energy diet [OR ( $95 \% \mathrm{CI})=$ $2.2(1.1$ to 4.3$)$, fathers' own SRH positive [OR $(95 \% \mathrm{CI})=3.0(1.5$ to 6.0$)$ ], and fathers not smoking [OR $(95 \% \mathrm{CI})=2.2(1.1$ to 4.4$)]$. In the final multivariable model $\left(\chi^{2}=45.3, \mathrm{df}=17, \mathrm{~N}=353, \mathrm{p}<0.001\right)$ four variables remained predictive of favourable SRH of children: mothers' SRH positive [OR $(95 \% \mathrm{CI})=6.2$ (2.1 to 17.7$)$ ], mothers consuming lower energy diet $[\mathrm{OR}(95 \% \mathrm{CI})=3.6$ (1.3 to 10.3)], family with high weekly household income [OR $(95 \% \mathrm{CI})=3.4(1.1$ to 10.4$)$ ], and fathers' employment status positive [OR $(95 \% \mathrm{CI})=$ 5.4 (1.0 to 28.2)].

Conclusion The findings substantiate the familial influence on child health during the early developmental stage, which is socially patterned and related particularly to economic circumstances.

\section{P2-475 HIV RISK BEHAVIOUR AND PREVALENCE OF SELF REPORTED SEXUALLY TRANSMITTED DISEASES AMONG MEN WHO HAVE SEX WITH MEN, REGISTERED WITH SELECTED NON-GOVERNMENTAL ORGANISATIONS IN DELHI, INDIA}

doi:10.1136/jech.2011.142976m.3

V Silan, S Kant, * K Goswami, S Rai, P Misra. All India Institute of Medical Sciences, New Delhi, India

Introduction In India HIV/AIDS rates are almost stable in high risk groups except among Men who have Sex with Men (MSMs). There are scarce data available on MSMs. The objective of this study was to assess knowledge, practices and risk behaviours and self-reported STIs among MSMs.

Methods A cross-sectional survey was conducted in three nongovernmental organisations working with MSM in Delhi. 250 MSMs were interviewed over a period of one year. This study examined MSM in the last six months.

Results The mean age of study participants was 24.6 years (SD \pm 5.8); $20 \%$ were adolescents. Most of the participants were well aware of the various routes of transmission of HIV/AIDS. However only half were using condoms. The number of sexual partners ranged from 1 to 20 per month. Nearly one-third (38.4\%) of participants were involved in sex for pay. The prevalence of selfreported STIs was $41.2 \%$.

Discussion A substantial proportion of participants were young, literate, often married. Reported knowledge in this study was higher than that in previous studies which was reflected in the practice of participants. NGOs have played a significant role in promoting safer sexual practices.

Conclusion The participants had adequate knowledge about HIV prevention. However, prevention practices were poor. A significant proportion of the MSM experienced one or more episode of the STIs. Perceived risk of getting HIV was high.

\section{P2-476 ASSOCIATION BETWEEN MATERNAL EXPOSURE TO BIOMASS SMOKE AND BIRTH WEIGHT: AN ANALYSIS OF 2005-2006 INDIA DEMOGRAPHIC HEALTH SURVEY DATA}

doi:10.1136/jech.2011.142976m.4

${ }^{1} \mathrm{C}$ Sreeramareddy, ${ }^{2} \mathrm{R}$ Shidhaye, ${ }^{3} \mathrm{~N}$ Sathiakumar. ${ }^{1}$ Melaka-Manipal Medical College, Melaka, Malaysia; ${ }^{2}$ Indian Institute of Public Health, Hyderabad, India; ${ }^{3}$ School of Public Health, University of Alabama at Birmingham, Birmingham, Alabama, USA

Introduction Observational epidemiological studies and a systematic review have consistently shown the association between maternal exposure to biomass smoke and reduced birth weight.

Methods We analysed 47139 most recent singleton births of 2005-2006 India DHS. Information on birth weight was obtained from health card or mothers' recall. "size of baby" at birth in a fivefold classification was re-coded as "smaller than average" and 